PEREZ, Clotilde (Org.) ; TRINDADE, E. (Org.) ; FOGACA, J. (Org.); BATISTA, Leandro Leonardo (Org.) . Universo Sígnico da Pirataria: Falso? Verdadeiro!. 1. ed. São Paulo: Inmod, 2013. v. 1.363p

\title{
CULTURA, MARCAS E PIRATARIA: O CONSUMO QUE NÃO TEM PREÇO.
}

\author{
Diogo Kawano ${ }^{1}$
}

É com grande prazer que recebi o convite para trazer aqui a resenha do livro “Universo Sígnico da Pirataria: Falso? Verdadeiro!”, lançado em novembro de 2013 pela editora Inmod.

Não digo que é um prazer por mero acaso. A publicação é resultado do trabalho multidiscplinar do Grupo de Estudos Semióticos em Comunicação, Cultura e Consumo $\left(\mathrm{GESC}^{3}\right.$ - ECA/USP), que desde 2007 traz valiosas reflexões unindo áreas como antropologia, filosofia, psicologia, marketing, moda e design para compreender de maneira transversal a dinâmica da comunicação e do consumo nas práticas sociais. Para tanto, o grupo reuniu a expertise de 30 pesquisadores, professores, alunos de graduação e pós-graduação, formados nas mais diversas áreas, para discutir com profundidade a temática da pirataria e o universo de sentido que o circunda.

Nesse sentido, o leitor é presenteado, já de início, com um prefácio elaborado pelo renomado antropólogo Massimo Canevacci, cujo texto ressalta a crise imbuída não somente nos direitos autorais intelectuais, como também nos produtos materiais, duas dimensões nas quais uma linha fronteiriça já não faz mais sentido na contemporaneidade, assim como a dualidade entre verdadeiro e falso, sintetizada pelo pensador simplesmente como fake, uma mistura semiótica e fetichista entre o verdadeiro e falso.

Tal construção é ponte vital para o que é discutido nos 11 capítulos nos quais o livro está organizado, ou seja, que as reflexões acerca da pirataria se tornam inestimavelmente mais ricas quando observadas por outras perspectivas que ultrapassam a abordagem simplista do consumo de itens piratas por questões de ordem financeira.

Desta forma, Clotilde Perez e Eneus Trindade abrem o primeiro capítulo abordando a escolha metodológica da antropologia visual e da fotoetnografia, de forma

\footnotetext{
${ }^{1}$ Mestrando do Programa de Pós-Graduação em Ciências da Comunicação - PPGCOM, da Escola de Comunicações e Artes da USP - ECA-USP. Bolsista CAPES. E-mail: drkawano@ gmail.com.
} 
Cultura, marcas e pirataria: o consumo que não tem preço.

de Diogo Kawano

a apresentar como o método se evidencia assaz rentável tanto para o estudo da pirataria como para o diálogo com outros métodos utilizados pelo GESC $^{3}$, como a semiótica de Peirce, a Análise do Discurso e demais técnicas qualitativas. É nesse cenário, apoiados por pensadores como Ribeiro (2003), Achutti (2004) e Pétonnet (1982), que os autores afirmam que a fotografia se constitui como uma importante aliada para a pesquisa do grupo na medida em que permite o registro a partir de um olhar sensível e inerente do pesquisador que vai a campo. $\mathrm{O}$ desapego às concepções estigmatizadas para observar o objeto de estudo, suas peculiaridades, contextos e semelhanças a outros objetos é, desta forma, parte dos três olhares a que o investigador deve estar atento: o metodológico, subjetivo e para o objeto de estudo.

No capítulo seguinte, Paulo Araújo inicia uma abordagem filosófica, ao pôr em questão a ideia ocidental de autoria, cuja origem se deu na Alemanha, durante seu período Romântico. Assim, é neste momento em que o indivíduo passa a ser reconhecido como sujeito capaz de produzir e representar algo que outros não tiveram a capacidade de fazê-lo, algo bastante diferente do período medieval, em que o artista era visto como sendo guiado por Deus e, portanto, isento de qualquer atribuição pela criação.

Contudo, o autor menciona que diante da lógica atual de consumo, a concepção de autoria se desconstrói, uma vez em que o criativo passa não mais a ser o foco por sua criação, mas sim assumindo um papel de manter uma marca em elevados patamares de consumo, alavancado pelo desejo simbólico que passa a residir não mais no corpo, mas fora dele, no objeto.

É justamente das motivações para a busca, compra e uso de marcas falsificadas que tratam Clotilde Perez, Eneus Trindade e Sérgio Barion no capítulo posterior, a partir das representações de consumo forjadas em uma sociedade do simulacro, conceito do filósofo Jean Baudrillard. Tecendo uma admirável relação entre pensadores que estudam os mecanismos, valores, cultura e consumo pós-moderno, atrelados à profusão de signos que dá dinamismo à roda da sociedade do hiperconsumo, os autores apontam e discutem cinco motivações-chaves que subjazem o consumo dos itens falsificados, que vão desde a aprovação pela posição distintiva do bem, às facilidades de aquisição e troca do produto, passando também por suas dimensões estéticas e financeiras.

Ademais, se por um lado o ocidente passou a reconhecer a autoria do sujeito, tratando-a com repúdio e passível de punições na esfera jurídica dos direitos autorais, de outro, a lógica que permeia o mercado da pirataria na China tem raízes milenares, 
Cultura, marcas e pirataria: o consumo que não tem preço.

de Diogo Kawano

calcada nos preceitos de sua cultura confucionista. É este retrato que Lawrence Koo dá acerca dos processos de cópia, aprendizagem e inovação, discutindo que a prática da cópia, na perspectiva da repetição constante em direção ao aprimoramento, não somente é positiva como também deve ser exercitada, já que é a partir da imitação que a inovação (como um passo além) se torna viável. O autor delineia um curioso panorama histórico do tema e traz uma analogia chinesa com o processo de desenvolvimento econômico pelo qual o Japão passou, na Era Meiji. É, de fato, uma visão desmistificadora dos aspectos preconceituosos que podem vir de um olhar mais ingênuo de um cidadão acostumado aos valores ocidentais.

Como nem sempre a cópia se apoia nos pilares do respeito e do desenvolvimento, Gino Giacomini Filho faz um contraponto muito bem documentado a respeito da imitação na propaganda comercial. Para isso, Giacomini apresenta os principais mecanismos legais e autorregulamentados que circunscrevem a comunicação mercadológica no Brasil e faz uma análise pontual de 50 representações no CONAR (órgão que regula a propaganda no país) envolvendo imitação para, então, observar tais aspectos do ponto de vista de quatro especialistas em publicidade, incluindo o vicepresidente do próprio CONAR. As entrevistas, associadas à análise das representações, destacam temas importantíssimos de ordem ética, concorrencial e criativa, constituindo uma ótima indicação de leitura àqueles que anseiam estudos dessa natureza.

No prosseguimento do livro, Alexandre las Casas e Wesley Pinheiro dedicam um capítulo para mostrar como a pirataria impactou diferentes segmentos de mercado, tais como a indústria fonográfica, editorial e farmacêutica, e como tal processo foi, em certa medida, facilitado pela cultura da cópia caseira propiciada pela inserção de equipamentos de cópia domésticos, como a fita K7 e o VHS. Atrelado a isso, o autor aponta ainda como a pirataria pode beneficiar marcas e produtos sob a perspectiva do marketing, aumentando o conhecimento de marca e possibilitando tanto a divulgação de bens culturais (caso do filme Tropa de Elite) como o seu domínio no mercado em que atua, como, por exemplo, a versão pirata do sistema operacional Windows.

Uma reflexão teórica complementar à abordagem dos autores é desenvolvida por Thaís Curtis, cujo capítulo perpassa pela quebra da relação entre o necessário e o supérfluo na sociedade hipermoderna, na qual o consumo passa a estar ligado muito mais aos valores sociais e marcários do que pela necessidade funcional propriamente dita dos bens produzidos. Nesse sentido é que atuam as marcas, criando e adequando suas representações na mente dos consumidores que agem na lógica do consumo 
Cultura, marcas e pirataria: o consumo que não tem preço.

de Diogo Kawano

sazonal, que ao se espalhar para a massa, produz uma força distintiva por parte dos mercados consumidores mais exigentes.

O reflexo do consumo e presença dos itens piratas, bem como suas implicações sociais e financeiras adquirem tamanha importância que passam a se materializar na forma de museus da contrafação (museus de pirataria). É assim que Eneus Trindade, Livia Souza e Nicolás Llano discutem em um texto teoricamente rico, bem articulado e com vasto uso de exemplos fotoetnográficos (Museu da Contrafação de Paris), como tais espaços se configuram tanto como locais de denúncia e educação contra o consumo pirata, como um fenômeno de exaltação de toda dinâmica que delimita a temática dos produtos contrafeitos.

Desta forma, os autores introduzem como a ideia de contrafação, tida como qualquer reprodução, imitação ou falsificação de bens industriais tem como origem de sua preocupação os pedidos de patentes advindos da indústria farmacêutica, ainda no século XIX, para então tecerem uma relação com os paradoxos da hipermodernidade mencionados por Lipovetsky. Deste modo, não é por acaso que tais museus não são paradoxais ao contexto atual, mas ao contrário: estão alinhados ao fato de que tudo é passível de ser celebrado e resgatado, inclusive os museus de pirataria e seus itens contrafeitos. Por fim, são ainda apresentadas as diferentes categorias que circunscrevem a contrafação, como falsificação, plágio, adaptação e pirataria, sempre que possível, ilustrados com exemplos do Museu da Contrafação de Paris.

É com base no mesmo aporte teórico que Jôse Fogaça e Silvio Sato põem em discussão a pirataria de itens de luxo, sobretudo os bens relacionados à moda, como bolsas e relógios. Para tanto, o capítulo aborda a sociedade de consumo e sua relação muito mais voltada às questões de expressão de identidade e estilos de vida, para as quais convergem os significados do universo culturamente constituído para os produtos e, então para o consumidor. Duas excelentes entrevistas em profundidade, uma com uma consumidora de classe social abastada e outra com uma vendedora de produtos piratas, ilustram de forma esclarecedora como as relações entre o consumo de luxo e pirataria são muito mais complexas quando vistas sob uma ótica transversal da sociedade.

Já o penúltimo capítulo do livro, de Jefferson Rezende, traz o olhar estrangeiro do mercado e consumo pirata de Tepito, região da capital mexicana. Ao longo do texto, o autor mostra semelhanças e diferenças de ordem social e econômica entre a cidade de São Paulo e a Cidade do México, e como esta última, somente pela região de Tepito, 
Cultura, marcas e pirataria: o consumo que não tem preço.

de Diogo Kawano

responde por inacreditáveis $14 \%$ do PIB do país (sete em cada dez produtos piratas consumidos no México são comercializados na região, segundo levantamento da Procuradoria Geral da República). Assim, apesar das semelhanças com o Brasil, o autor relata a forma surpreendente as relações e apropriações de significados pela população local, cuja compra envolve até títulos falsificados de doutorado pela Universidad Nacional Autónoma de México, a UNAM.

Por fim, o último capítulo ${ }^{2}$ do livro contempla a vasta pesquisa realizada pelos integrantes do $\mathrm{GESC}^{3}$, em uma integração das reflexões teóricas e empíricas estudadas pelo grupo, e que remete ao primeiro tópico abordado no texto, ou seja, os desafios metodológicos da pesquisa de campo: a fotoetnografia e as entrevistas em profundidade.

A partir da observação em campo de quatro grandes centros de comércio popular e pirata, a saber: (1) a região da 25 de Março, em São Paulo, (2) a Feira dos Importados em Brasília, (3) a região do SAARA, no Rio de Janeiro e (4) a região de Tepito, na Cidade do México, os pesquisadores apresentam com maestria como lidaram com as dificuldades e sutilezas de coletar dados em um espaço que, por natureza própria, tende a ser aversivo à presença de pessoas tirando fotos dos produtos, dos vendedores e desejando que estes falem a respeito de como veem e entendem o comércio pirata (detalhes que deixo para o leitor desvendar na própria leitura do livro).

Diversas são as descobertas que resultaram da ida a campo, mas cabe destacar alguns aspectos, como a presença heterogênea de consumidores de artigos piratas, no que se refere a todos os estratos socioeconômicos, diferenças nas motivações de compra e de busca por diferentes atributos nos produtos, e sub-segmentação destes, os quais possuem posicionamento de preço distintos, consoante suas características visuais e qualidades de material empregado.

Creio que a esta altura já não seja mais necessário evidenciar o quão valiosa é essa obra para um melhor entendimento não somente do consumo pirata em si, mas acima de tudo, da vasta dimensão simbólica de sentidos que envolve a esfera do consumo e da cultura, temas que os autores mostram dominar com toda excelência e rigor científico. Como se viu, o livro tem como pontos fortes a capacidade de tratar do tema de forma clara, sistemática e multidisciplinar, sendo uma leitura que agrega novos saberes e amplia novas e profícuas dimensões metodológicas no campo.

\footnotetext{
${ }^{2}$ Em virtude do maior número de autores deste capítulo, optei por mencioná-los aqui, a fim de facilitar o fluxo de leitura do texto. Os autores são: Jôse Fogaça, Silvio Sato, Clotilde Perez, Alhen Damasceno, Cecília Cury, Lawrence Koo, Cinira Baader e Raquel Cardoso.
} 
Cultura, marcas e pirataria: o consumo que não tem preço.

de Diogo Kawano

\section{REFERÊNCIAS BIBLIOGRÁFICAS}

ACHUTTI, L. E. R. Fotoetnografia. Porto Alegre: Ed. UFRGS/Tomo Editorial, 2004.

PÉTONNET, C. L'observation flottante. L'exemple d'un cimetière parisien. L'Homme, Paris, vol. 22, $\mathrm{n}^{\circ} 4$, p. 37-47, 1982.

RIBEIRO, J. S. Métodos e técnicas de investigação em antropologia. Lisboa: Universidade Aberta, 2003.

Artigo submetido: 25/03/2013

Artigo aprovado: 18/09/2013 